\title{
Analisis Risiko Produksi Bawang Merah di Desa Songan B, Kecamatan Kintamani, Kabupaten Bangli
}

\author{
ANJELINA PUTRI, RATNA KOMALA DEWI, \\ I DEWA AYU SRI YUDHARI \\ Program Studi Agribisnis, Fakultas Pertanian, Universitas Udayana \\ Jl. PB. Sudirman Denpasar 80232 \\ Email: anjelinaputri45@gmail.com \\ ratnadewi61@ymail.com
}

\begin{abstract}
Risk Analysis of Red Onion Production in Songan B Village Kintamani District, Bangli Regency
\end{abstract}

Songan B Village is one of the villages that develop onion farming. Songan B village has farmer groups spread from the lowland to the highland areas. The problems faced are on the fluctuation of onion productivity which indicates that onion farming faces production risk. This study aimed to identify the types of risks and analyze the risk of onion production. This research used quantitative and qualitative analysis. The results showed that the types of production risks encountered in onion farming in the highland and lowland areas in the village of Songan B, namely climatic conditions, pest, and disease attacks. The risk of onion production in the highland areas $(\mathrm{KV}=3.09)$ and lowland areas $(\mathrm{KV}=2.46)$ was relatively high, where the level of risk of onion production in the highland areas was greater than that in the lower regions. This is due to the expected production, variant, and standard deviation of onion productivity in the highland areas is greater than that in the lower regions. The suggestion that can be given in this research is that farmers need to recognize the types of production risks faced in order to anticipate production decline.

Keywords: red onion, production risk, productivity

\section{Pendahuluan}

\subsection{Latar Belakang}

Usaha di bidang pertanian sangat dipengaruhi oleh iklim. Keadaan semacam ini berpotensi terhadap intensitas serangan hama yang dapat menyebabkan terjadinya risiko produksi hasil pertanian. Komoditas hortikultura adalah salah satu komoditi bahan pangan yang mendapatkan perhatian pemerintah. Komoditi ini merupakan salah satu bagian dari sektor pertanian yang diharapkan menjadi andalan bagi pertumbuhan ekonomi di masa mendatang. Jenis komoditas hortikultura yang sangat beragam mengharuskan pemerintah untuk melakukan prioritas pengembangan yang didasarkan pada beberapa pertimbangan, antara lain dapat meningkatkan pendapatan petani, mempunyai nilai gizi yang tinggi, menyerap tenaga kerja, mempunyai prospek pasar yang baik, dan dapat menambah devisa negara. 
Salah satu komoditas hortikultura adalah komoditas bawang merah. Menurut Purba (2002), bawang merah merupakan komoditas yang mempunyai kemampuan menaikkan tingkat pendapatan petani, sebagai bahan baku hampir disemua industri makanan, dibutuhkan setiap saat sebagai bumbu masak, obat tradisional, berpeluang ekspor dan dapat membuka kesempatan kerja. Propinsi Bali mempunyai tiga kabupaten yang memiliki produksi bawang merah relatif banyak, yaitu Bangli, Karangasem, dan Buleleng. Kabupaten Bangli memiliki produksi bawang merah terbanyak yaitu 9.556 ton $(94,17 \%)$ di Propinsi Bali (Badan Pusat Statistik Bali, 2016). Menurut Badan Pusat Statistik Kabupaten Bangli (2016), Kecamatan Kintamani memiliki tingkat produktivitas bawang merah tertinggi di antara empat kecamatan di Kabupaten Bangli (Kecamatan Susut, Kecamatan Bangli, Kecamatan Tembuku, dan Kecamatan Kintamani). Keadaan ini mengindikasikan adanya risiko yang dihadapi oleh petani bawang merah di Kecamatan Kintamani.

Desa Songan B merupakan salah satu sentra produksi bawang merah di Kecamatan Kintamani yang memiliki wilayah administratif seluas $11,88 \mathrm{~km}^{2}$ dan memiliki ketinggian 80-1200 mdpl. Desa Songan B mengembangkan usahatani bawang merah secara tumpang gilir bersama tomat, cabai, atau kol (Laporan Desa Songan B Tahun 2016). Usahatani bawang merah yang ada di Desa Songan B tergabung dalam Gabungan Kelompok Tani (Gapoktan) Asta Mandiri. Kelompok tani tersebut terdiri atas 50 kelompok tani yang tersebar di daerah bawah hingga daerah atas. Oleh karena itu, untuk mengetahui indikasi adanya risiko produksi bawang merah maka dilihat produktivitas bawang merah pada daerah atas dan daerah bawah yang diwakili oleh satu kelompok tani yaitu Kelompok Tani Dwi Sari Unggul untuk daerah atas dan Kelompok Tani Ternak Merta Jaya untuk daerah bawah.

\subsection{Tujuan Penelitian}

Tujuan penelitian adalah 1). mengidentifikasi jenis-jenis risiko yang dihadapi oleh petani bawang merah di Desa Songan B Kecamatan Kintamani Kabupaten Bangli, dan 2). menganalisis tingkat risiko yang dihadapi oleh petani bawang merah di Desa Songan B Kecamatan Kintamani Kabupaten Bangli.

\section{Metodologi Penelitian}

\subsection{Tempat dan waktu penelitian}

Penelitian ini telah dilaksanakan pada kelompok tani bawang merah yang berada di daerah atas (Kelompok Tani Sari Dwi Unggul) dan kelompok tani yang ada di daerah bawah (Kelompok Tani Ternak Merta Jaya) pada musim tanam Bulan Desember 2015 s.d Bulan Februari tahun 2016. Pemilihan lokasi dilakukan secara purposive dengan pertimbangan karena Desa Songan B merupakan salah satu sentra produksi bawang merah di Kecamatan Kintamani yang memiliki lahan usahatani bawang merah tersebar pada ketinggian 80-1200 mdpl.

\subsection{Metode Pengumpulan Data, data, dan variabel penelitian}

Data yang digunakan dalam penelitian ini bersumber dari data primer dan data sekunder. Data primer diperoleh langsung dari hasil observasi dan wawancara, sedangkan data sekunder diperoleh dari studi-studi sebelumnya yang terkait. Variabel dalam penelitian ini adalah jenis-jenis risiko dan tingkat risiko produksi bawang merah. 


\subsection{Sampel dan Teknik pengambilan sample}

Sampel penelitian diambil dari populasi petani bawang merah di Desa Songan B tahun 2016. Penentuan jumlah sampel menggunakan metode sensus, yaitu pemilihan sampel dilakukan dengan menjadikan seluruh populasi sebagai sumber data untuk mendapatkan informasi yang akurat. Pemilihan sampel berdasarkan ketinggian lokasi di Desa Songan B yaitu Kelompok Tani Dwi Sari Unggul (18 orang petani) dan Kelompok Tani Ternak Merta Jaya (20 orang petani).

\subsection{Metode analisis data}

Metode analisis data yang digunakan dalam penelitian ini adalah (1) untuk mengidentifikasi jenis-jenis risiko produksi bawang merah menggunakan analisis deskriptif kualitatif dan (2) untuk menganalisis tingkat risiko produksi digunakan analisis kuantitatif dengan rumus antara lain:

\subsubsection{Probabilitas}

Mengetahui probabilitas atau peluang kemungkin terjadinya suatu peristiwa. Menurut Darmawi (2004), Secara sistematis peluang dapat dirumuskan dengan

$$
\mathrm{P}=\frac{\mathrm{F}_{\mathrm{i}}}{\mathrm{n}}
$$

Keterangan:

$\mathrm{P} \quad=$ Peluang

fì $\quad=$ Frekuensi masing - masing kondisi

$\mathrm{n} \quad=$ Jumlah responden

\subsubsection{Nilai harapan (ekspektasi produksi)}

Nilai harapan yang digunakan sebagai pertimbangan dalam pengambilan keputusan untuk melanjutkan kegiatan usaha. Secara sistematis nilai harapan atau ekspektasi produksi dapat ditulis dengan rumus sebagai berikut.

$$
E(\mathrm{Q})=\sum_{i=1}^{\mathrm{n}} \mathrm{Q}_{\mathrm{i}} . \mathrm{P}_{\mathrm{i}}
$$

Keterangan

$E(\mathrm{Q})=$ Nilai yang diharapkan dari produktivitas bawang merah (kg/are)

$\mathrm{Q}_{\mathrm{i}} \quad=$ Produktivitas bawang merah (kg/are)

$\mathrm{P}_{\mathrm{i}} \quad=$ Probabilitas dari produktivitas bawang merah

\subsubsection{Varian}

Pengukuran varian dari produktifitas bawang merah dapat dituliskan dengan rumus sebagai berikut

$$
\sigma^{2}=\sum_{\mathrm{i}=1}^{n}\left(\mathrm{Q}_{\mathrm{i}}-E(\mathrm{Q})\right)^{2} \cdot \mathrm{P}_{\mathrm{i}}
$$

Keterangan

$\sigma^{2} \quad=$ Varian dari produktifitas bawang merah $(\mathrm{kg} / \mathrm{are})$

$\mathrm{Pi} \quad=$ Probabilitas

Qi = Produktivitas bawang merah $(\mathrm{kg} / \mathrm{are})$

$E(\mathrm{Q})=$ Expected production bawang merah $(\mathrm{kg} / \mathrm{are})$ 
Nilai varian dapat menunjukkan bahwa semakin kecil nilai varian maka semakin kecil penyimpangannya sehingga semakin kecil risiko yang dihadapi dalam melakukan kegiatan usaha tersebut.

\subsubsection{Standar deviasi} berikut.

Mengetahui nilai standar deviasi dapat ditulis dengan dengan rumus sebagai

$$
\sigma=\sqrt{\sigma^{2}}
$$

Keterangan

$\sigma \quad=$ Standar deviasi produktivitas bawang merah

$\sigma^{2} \quad=$ Nilai varian dari produktivitas bawang merah $(\mathrm{kg} / \mathrm{are})$

\subsubsection{Koefisien variasi}

Koefisien variasi merupakan ukuran yang bebas dimensi, atau angka murni yang dapat digunakan untuk membandingkan risiko relatif dari dua proyek atau usaha maupun yang lebih dari dua proyek atau usaha. Usahatani yang memiliki koefisien variasi paling tinggi adalah usahatani yang paling berisiko (Salvatore, 2003). Kriteria yang dipakai dalam penelitian ini adalah apabila nilai koefisien variasi $(\mathrm{KV})<1$, maka usahatani bawang merah memiliki risiko produksi yang kecil dan sebaliknya jika nilai koefisien variasi $(\mathrm{KV}) \geq 1$, maka usahatani bawang merah memiliki risiko produksi yang besar (Fauziyah, 2011).

Menurut Elton dan Guber (dalam Purnama 2012), koefisien variasi dirumuskan dengan.

$$
\mathrm{KV}=\frac{\sigma}{E(\mathrm{Q})}
$$

Keterangan

$\mathrm{KV}=$ Koefisien variasi produktivitas bawang merah

$\sigma \quad=$ Standar variasi produktivitas bawang merah $(\mathrm{kg} / \mathrm{are})$

$E(\mathrm{Q})=$ Expected production bawang merah ( $\mathrm{kg} / \mathrm{are})$

\section{Hasil dan Pembahasan}

\subsection{Karakteristik Petani Bawang Merah}

Karakteristik petani bawang merah yang diamati dalam penelitian ini meliputi umur, tingkat pendidikan, dan luas garapan. Karakteristik petani tersebut dapat dilihat pada Tabel 1. 
Tabel 1.

Karakteristik Petani Bawang Merah di Desa Songan B Kecamatan Kintamani Kabupaten Bangli

\begin{tabular}{|c|c|c|c|c|}
\hline \multirow[b]{2}{*}{ No } & \multirow[b]{2}{*}{ Karakteristik } & \multicolumn{3}{|c|}{ Jumlah petani } \\
\hline & & Kategori & Orang & $\begin{array}{c}\text { Persentase } \\
(\%)\end{array}$ \\
\hline \multirow[t]{2}{*}{1} & Umur & $15-60$ tahun & 34 & 89,47 \\
\hline & & $60+$ tahun & 4 & 10,52 \\
\hline \multirow[t]{5}{*}{2} & Pendidikan & Tidak sekolah & 3 & 7,89 \\
\hline & & SD & 26 & 68,42 \\
\hline & & SMP & 4 & 10,52 \\
\hline & & SMA & 3 & 7,89 \\
\hline & & Sarjana & 2 & 5,26 \\
\hline \multirow[t]{3}{*}{3} & Luas lahan garapan & $<50$ are & 19 & 50,00 \\
\hline & & $50-200$ are & 19 & 50,00 \\
\hline & & $\geq 200$ are & 0 & 0,00 \\
\hline
\end{tabular}

Sumber: Diolah dari data primer,2016

Mayoritas petani bawang merah Desa Songan B berada pada usia produktif $(89,47 \%)$, dan berpendidikan relatif rendah yaitu tamat SD $(68,42 \%)$. Jumlah petani bawang merah yang memiliki luas lahan yang sempit sama banyak dengan petani yang memiliki lahan sedang yaitu masing-masing sebanyak 19 orang petani (50\%). Semakin luas lahan garapan yang diusahakan petani, maka akan semakin besar produksi yang dihasilkan dan pendapatan yang akan diperoleh bila disertai dengan pengolahan lahan yang baik (Soekartawi, 1990).

\subsection{Identifikasi Jenis - Jenis Risiko Usahatani Bawang Merah}

Jenis-jenis risiko yang sering dihadapi oleh petani bawang merah di daerah atas dan di daerah bawah pada dasarnya sama yaitu kondisi iklim yang sulit diprediksi serta serangan hama dan penyakit tanaman bawang merah.

a. Kondisi iklim usahatani bawang merah di Desa Songan B

Desa Songan B memiliki kondisi iklim yang sulit untuk diprediksi serta curah hujan yang berubah-ubah setiap musimnya merupakan salah satu jenis risiko bagi produksi bawang merah. Cuaca yang ada di daerah atas sedikit berbeda dibandingkan di daerah bawah. Cuaca yang berada di daerah atas memiliki curah hujan yang relatif lebih rendah daripada di daerah bawah dan di daerah atas juga memiliki kelembaban udara yang rendah karena tingkat udara yang terbilang kering.

Bawang merah merupakan tanaman yang paling baik ditanam dilahan terbuka dengan kondisi pencahayaan $70 \%$. Keadaan ini akan memberi sinar matahari yang cukup bagi pertumbuhan bawang merah. Bawang merah memerlukan penyinaran matahari 12 jam setiap harinya. Suhu daerah yang mendukung pertumbuhan bawang merah adalah sekitar 25 s.d $35{ }^{\circ} \mathrm{C}$ sedangkan batas keasaman tanah berkisar antara ph 5,6 s.d tujuh. Kondisi inilah yang menyebabkan adanya indikasi risiko produksi bawang merah di Desa Songan B yang membuat produksi bawang merah bersifat fluktuatif (Dispertahortnakbun Pesisir Selatan, 2012). 
b. Hama dan penyakit yang dihadapi petani bawang merah di Desa Songan B

Hama dan penyakit yang menyerang tanaman bawang merah pada musim tanam Bulan Desember 2015 s.d Bulan Februari 2016 adalah ulat daun, ulat tanah, dan penyakit layu fusarium/moler. Hama dan penyakit yang menyerang tanaman bawang merah di daerah atas dan bawah pada dasarnya sama dan petani menggunakan cara yang sama juga dalam memusnahkan hama yang menyerang tanaman bawang merah yaitu menggunakan perangkap sebagai umpan.

\subsection{Analisis Tingkat Risiko Usahatani Bawang Merah}

Kegiatan untuk menganalisis tingkat risiko dimulai dengan mengukur tingkat probabilitas produktivitas bawang merah. Menganalisis tingkat risiko produksi bawang merah ini menggunakan data produktivitas yang dikelompokkan dalam tiga tingkatan yaitu tinggi, sedang, dan rendah. Produktivitas beserta peluang pada masing-masing tingkatan dapat disajikan pada Tabel 2.

\section{Tabel 2.}

Rata - Rata Produktivitas Bawang Merah dan Peluang yang dihadapi Kelompok Tani di Desa Songan B

\begin{tabular}{llcccc}
\hline No & $\begin{array}{c}\text { Tingkatan } \\
\text { produktivitas }\end{array}$ & $\begin{array}{c}\text { Produktivitas di } \\
\text { kelompok tani } \\
\text { daerah atas } \\
(\mathrm{kg} / \mathrm{are})\end{array}$ & Peluang & $\begin{array}{c}\text { Produktivitas di } \\
\text { kelompok tani } \\
\text { daerah bawah } \\
\text { (kg/are) }\end{array}$ & Peluang \\
\hline 1 & Tinggi & $85,55-106,67$ & 0,78 & $56,66-80$ & 0,35 \\
2 & Sedang & $64,44-85,55$ & 0,17 & $33,33-56,66$ & 0,50 \\
3 & Rendah & $43,33-64,44$ & 0,06 & $10-33,33$ & 0,15 \\
\hline
\end{tabular}

Sumber: dioleh dari data primer, 2016.

Pada Tabel 2 ditunjukkan range produktivitas untuk kelompok tani yang ada di daerah atas yaitu 43,33 kg/are s.d 106,67 kg/are, sedangkan range produktivitas untuk kelompok tani yang ada di daerah bawah yaitu $10 \mathrm{~kg} / \mathrm{are}$ s.d $80 \mathrm{~kg} / \mathrm{are}$. Produktivitas kelompok tani daerah atas sebagian besar berada pada produktivitas tinggi (78\%) dan produktivitas kelompok tani daerah bawah sebagian besar berada pada produktivitas sedang (50\%). Berdasarkan data produktivitas bawang merah di daerah atas dan bawah, maka dapat diketahui tingkat risiko produksi melalui perhitungan expected production, varian, standar deviasi, dan koefisien variasi. Hal ini disajikan pada Tabel 3. 
Tabel 3.

Expected production, Varian, Standar deviasi, Koefisien variasi Produktivitas Bawang Merah di Desa Songan B Bulan Desember s.d Bulan Februari 2016

\begin{tabular}{clc}
\hline Kelompok Tani & Ukuran & Nilai (Kg/are/musim) \\
\hline \multirow{4}{*}{ Di Daerah atas } & Expected production & $1.113,22$ \\
& Varian & 11.857 .096 \\
& Standar deviasi & $3.443,41$ \\
& Koefisien variasi & 3,09 \\
& Expected production & 417,31 \\
& Varian & $1.051 .263,28$ \\
Di Daerah bawah & Standar deviasi & $1.025,31$ \\
& Koefisien variasi & 2,46 \\
\hline
\end{tabular}

Sumber: Diolah dari data primer, 2016

Berdasarkan Tabel 3 di atas dapat dilihat bahwa koefisien variasi dari produktivitas usahatani bawang merah pada kelompok tani di daerah atas pada musim tanam Bulan Desember 2015 s.d Bulan Februari 2016 yaitu 3,09, artinya setiap 1.000 kali panen memiliki peluang gagal panen sebanyak 309 kali dari nilai produktivitas yang diharapkan oleh petani, demikian pula hasil koefisien variasi dari produktivitas usahatani bawang merah pada kelompok tani di daerah bawah pada musim tanam Bulan Desember 2015 s.d Bulan Februari 2016 yaitu 2,46 artinya setiap 1.000 kali panen memiliki peluang gagal panen sebanyak 246 kali dari nilai produktifitas yang diharapkan oleh petani.

Tingkat risiko produksi yang dihadapi dalam usahatani bawang merah pada kelompok tani bawang merah di Desa Songan B yang berada di daerah atas $(3,09)$ lebih besar dari pada kelompok tani yang ada di daerah bawah $(2,46)$. Hal ini disebabkan oleh expected production, varian, standar deviasi produktivitas usahatani bawang merah pada kelompok tani di daerah atas lebih tinggi daripada di daerah bawah.

\section{Kesimpulan dan Saran}

\subsection{Kesimpulan}

Berdasarkan hasil analisis dan pembahasan maka, dapat disimpulkan bahwa:

1. Jenis - jenis risiko yang dihadapi kelompok tani bawang merah yaitu kondisi iklim yang sulit diprediksi serta hama dan penyakit tanaman bawang merah.

2. Tingkat risiko produksi bawang merah di Desa Songan B di daerah atas lebih tinggi dibandingkan di daerah bawah.

\subsection{Saran}

Saran yang dapat diberikan dalam penelitian ini adalah

1. Kondisi iklim yang sulit diprediksi dapat di atasi dengan mengelola budidaya bawang merah lebih baik antara lain menetapkan jadwal tanam yang tepat, menggunakan bibit unggul, penggunaan mulsa plastik. Perlindungan terhadap tanaman perlu dilakukan dengan teratur untuk mencegah munculnya serangan hama dan penyakit.

2. Fluktuasi produktifitas bawang merah dapat mempengaruhi pendapatan petani. Oleh karena itu, perlu diadakan penelitian lanjutan terhadap tingkat risiko 
pendapatan serta faktor-faktor yang mempengaruhi risiko pendapatan bawang merah.

\section{Ucapan Terima Kasih}

Penulis menyampaikan terimakasih kepada pihak yang telah memberikan informasi yang mendukung penelitian yaitu Ketua Kelompok Tani Ternak Merta Jaya, Ketua Kelompok Tani Dwi Sari Unggul, Dinas Pertanian Kabupaten Bangli, seluruh responden serta PPL Desa Songan B.

\section{Daftar Pustaka}

Anonim. 2016. Laporan Desa Songan B. Kintamani. Bangli

Badan Pusat Statistik. 2016. Bali Dalam Angka. Produksi Sayur - Sayuran dirinci Menurut Jenisnya dan Kabupaten/Kota di Bali 2015 http://www.bps.go.id Diakses pada 1 November 2016

Badan Pusat Statistik. 2016. Bangli Dalam Angka. Produksi Bawang Merah di Kabupaten/Kota (ton/ha) di Bali Tahun 2011 - 2015 http://www.bps.Bangli.go.id Diakses pada 1 November 2016

Dinas Pertanian Tanaman Pangan, Pemerintah Kabupaten Pesisir Selatan. 2012. Pengelolaan Tanaman Terpadu Budidaya Tanaman Bawang Merah.Sumbar

Darmawi. 1997. Manajemen risiko. Bumi aksara. Jakarta

Fauziyah, E. 2011. Manajemen Risiko pada Usahatani Padi Sebagai Salah Satu Upaya Dalam Mewujudkan Ketahanan Pangan Rumah Tangga Petani (Studi Kasus di Desa Telang Kecamatan Kamal). Skripsi tidak dipublikasikan. Program Studi Agribisnis Fakultas Pertanian Universitas Trunojoyo Bangkalan. http://www.pertanian.trunojoyo.ac.id Diakses pada 26 April 2017

Salvatore, Dominick. 2003. Managerial Economics dalam Perekonomian Global

Edisi Keempat Jilid 2. Erlangga. Jakarta.

Soekartawi. 1990. Teori Ekonomi Produksi: Dengan Pokok Bahasan Analisis Cobb Douglas. Rajawali Pers: Jakarta

Purba, A R. 2002. Analisis Keunggulan Komparatif dan Kompetitif Usahatani Bawang Merah di Desa Lamajang, Kecamatan Pangalengan, Kabupaten Bandung. Jabar. Skripsi tidak dipublikasikan. Skripsi Jurusan SosekPert. IPB

Purnama Sari, Fitria. 2012. Analisis Risiko Produksi Pembenihan Melon di CV Multi Global Agrindo, Kecamatan Karangpandan, Kabupaten Karanganyar, Jawa Tengah. Institut Pertanian Bogor. Bogor. Skripsi tidak dipublikasikan. Departemen Agribisnis. Program Studi Ekonomi dan Bisnis Institut Pertanian Bogor. 